\title{
THz reflectometric imaging of medieval wall paintings
}

\author{
Dandolo, Corinna Ludovica Koch; Jepsen, Peter Uhd
}

\section{Published in:}

Proceedings of the 38th International Conference on Infrared, Millimeter and Terahertz Waves IRMMW-THz 2013

Link to article, DOI:

10.1109/IRMMW-THz.2013.6665839

Publication date:

2013

Link back to DTU Orbit

Citation (APA):

Dandolo, C. L. K., \& Jepsen, P. U. (2013). THz reflectometric imaging of medieval wall paintings. In Proceedings of the 38th International Conference on Infrared, Millimeter and Terahertz Waves IRMMW-THz 2013 IEEE. https://doi.org/10.1109//RMMW-THz.2013.6665839

\section{General rights}

Copyright and moral rights for the publications made accessible in the public portal are retained by the authors and/or other copyright owners and it is a condition of accessing publications that users recognise and abide by the legal requirements associated with these rights.

- Users may download and print one copy of any publication from the public portal for the purpose of private study or research.

- You may not further distribute the material or use it for any profit-making activity or commercial gain

- You may freely distribute the URL identifying the publication in the public portal 


\title{
$\mathrm{THz}$ reflectometric imaging of medieval wall paintings
}

\author{
Corinna L. K. Dandolo and Peter Uhd Jepsen \\ DTU Fotonik - Department of Photonics Engineering, Technical University of Denmark, \\ DK-2800 Kongens Lyngby, Denmark
}

\begin{abstract}
Terahertz time-domain reflectometry has been applied to the investigation of a medieval Danish wall painting. The technique has been able to detect the presence of carbonblack layer on the surface of the wall painting and a buried insertion characterized by high reflectivity values has been found in depth of the lime-based historical plaster.
\end{abstract}

\section{INTRODUCTION AND BACKGROUND}

$\mathrm{T}$ rahertz time-domain imaging enables a combination of tomographic and spectroscopic information of objects under investigation, and has recently become a powerful tool for investigation of mural paintings [1,2]. Modern portable devices that allows on-site examination evidently finds useful application in characterization of unmovable artifacts, being capable of noninvasive inspection of surface and buried layers. In this study, terahertz time domain reflectometry has been applied on-site for the investigation of a Danish medieval wall painting.

\section{Results And Discussion}

We have applied a portable $\mathrm{THz}$ imaging instrument (Picometrix T-Ray 4000) for the examination of the partly uncovered apsidal wall painting of Nebbelunde Church (Rødby, Lolland, Denmark), built in large monk bricks. The investigated medieval wall painting (Fig. 1(a)) is of Gothic style and depicts Saint Anne, sitting on a bench with the infant Mary, holding a book on her left hand, and the Christ in glory on the right. The pictorial technique used is the traditional medieval Danish one, which typically employs copper based green pigment, carbon-black and earths [3]. After the reformation the wall painting was covered by a thick layer of lime wash. Despite the past uncovering intervention, some lime-based mortar remains are still present on the surface.

Fig. 1(b) shows the investigated area and Fig. 1(c) the grayscale terahertz reflection image, plotted using the value of the difference between maximum and minimum of the temporal amplitude of the reflected terahertz signal. Despite the characteristic high reflectivity of carbon-based pigment in the terahertz range, the outlines of the figures, painted with carbon-black, are not always visible in the image due to strong scattering from the irregular surface. Regardless of this, it is possible to identify the carbon-black distribution in some painting details, including the outlines of Mary fingers (especially the index), the normal outlines which define the bottom of book (particularly the one of the open page) and, even if pale, the two curved outlines defining the draperies of the dress that falls to her knees.
The reflection image (Fig. 1(c)) clearly localizes the incisions made on the wet lime-based plaster by an awl as preparatory drawing of the Mary's fingers (specially marked for the pinky) before the pigment application, which do not always overlap with the final painted outlines. This proves that the artist has changed his mind as to the composition during the process of painting ("pentimenti"). All the surface scratches appear highlighted, with an effect similar to that of grazing visible light. The lower, middle part of Fig. 1(c) shows a dark " $\Gamma$ " shape mark that has no counterpart in the visible image. 3D visualization of the time-of-flight of the signal reflected at the surface (Fig. 2) reveals that this mark is related to an abrupt depression of $2-3 \mathrm{~mm}$ of the wall at that point. The uncovered regions of the wall painting are characterized by a smooth appearance of the $\mathrm{THz}$ reflection image, whereas the regions still covered by lime wash appears much more uneven in the $\mathrm{THz}$ image. This correlates well with the visual appearance of the area.

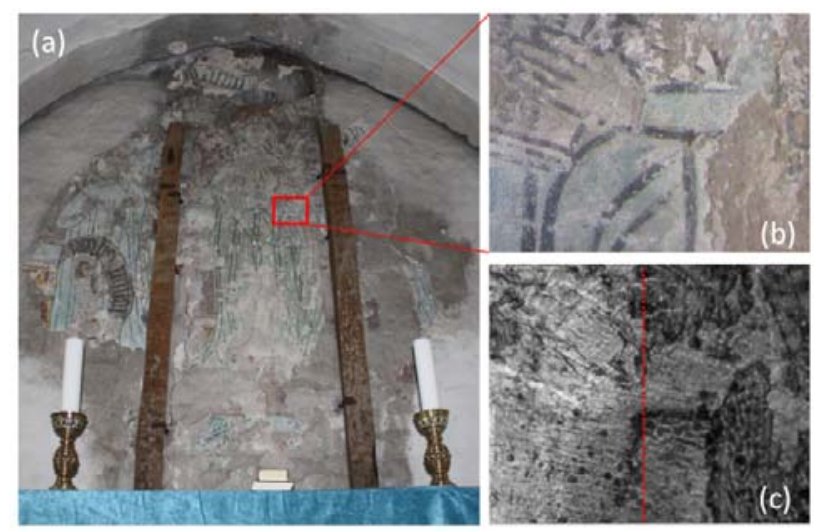

Fig. 1: (a) Apsidal wall painting in Nebbelunde Church - Rødby, Lolland, Denmark. (b) The relevant detail of the painting. (c) $\mathrm{THz}$ reflection image of the detail; the red line indicate the scan-line used to image the b-scan shown in Fig. 3.

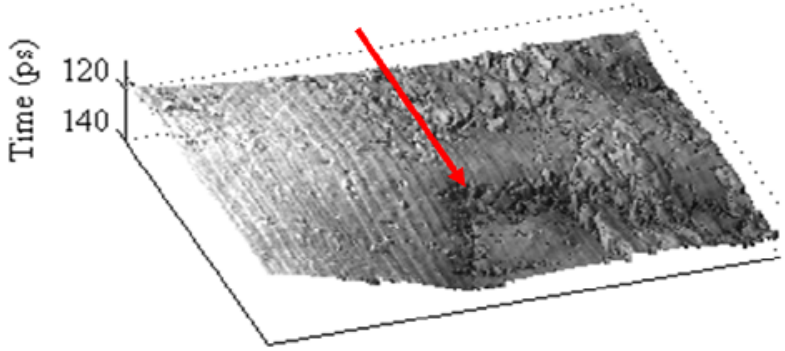

Fig. 2: 3D time-of-flight reflection plot of the scanned surface. The red arrow points the abrupt depression of the wall which cause the dark " $\Gamma$ " shape mark to appear in the THz reflection image in Fig. $1(\mathrm{c})$. 
B-scan images have been realized to represent non-invasive cross sections of the wall. The most interesting information arising from the b-scans is the presence of a hidden structure in depth in the plaster. Fig. 3 shows the b-scan image obtained by scanning the investigated area along the red line shown in Fig. 1(c), within the $260-320$ picoseconds range.

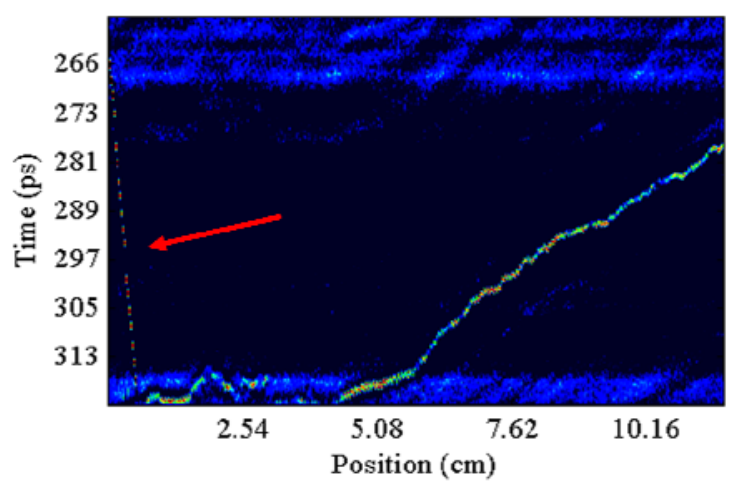

Fig. 3: b-scan along the red line in Fig. 1(c) revealing a subsurface structure, indicated by the red arrow.

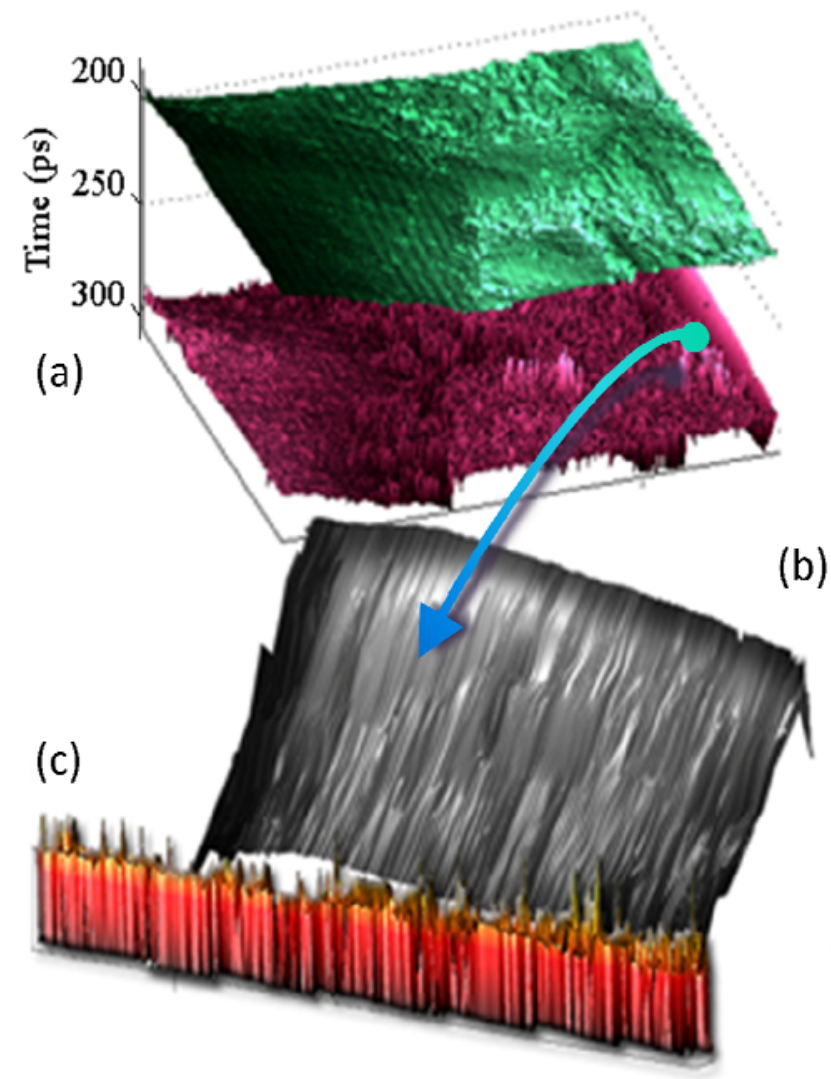

Fig. 4: b-scan along the red line in Fig. 1(c) revealing a subsurface structure, indicated by the red arrow.

Inside this temporal interval, at about 150 picoseconds after the arrival time of the main pulse, we note the presence of a thin insertion, transverse to the plaster, highlighted by the red arrow in Fig. 3. Due to the speed of light (c), 1 picosecond flight time $(\Delta \mathrm{t})$ of the terahertz signal corresponds to $0.3 \mathrm{~mm}$ distance $(\Delta \mathrm{x})$ in air. Assuming a mean index of refraction (n) equal to 1.5 for the building material, it may be calculated that the insertion is located at about $1.5 \mathrm{~cm}$ from the surface $(\Delta \mathrm{x}=$ $\mathrm{c} \Delta \mathrm{t} / 2 \mathrm{n}$, where the factor of 2 comes from the double-pass reflection geometry). Fig. 4(a) shows the $3 \mathrm{D}$ plot of the time time-of-flight of the signal reflected at the surface (green in the figure) and the time time-of-flight of the signal reflected within the 260 - 320 picoseconds interval (pink in the figure). We clearly identify a foil structure, inserted transversely into the wall. Detail of the insertion is shown in Fig. 4(b). The foil insertion is found to be in contact with a building element which may be attributed to a slab, given its characteristic texture (Fig. 4(c)). The concrete texture which can be observed in the 3D plot of the time time-of-flight of the signal reflected within the 260 - 320 picoseconds interval (Fig. 4(a)) is actually an echo image of the surface layer; it cannot be identified for the entire length of the scanned area since some part are located at times higher than 320 picoseconds (i.e. limit of the temporal window of the system).

In conclusion, we have investigated a medieval wall painting on-site with a portable $\mathrm{THz}$ imaging system. Thin layers of carbon black were visualized at the painting surface. A buried foil insertion characterized by high reflectivity values has been found in depth of the lime-based plaster of the wall painting. The identified foil appears to be in contact with a building element which may be attributed to a slab, whose texture has been identified. It has been so proved the capability of the technique in detecting buried reinforcements or inclusions inside historical masonry structures.

\section{ACKNOWLEDGMENT}

The authors would like to thank Mads Christian Christiansen, head of the Research, Analysis and Consultancy - Conservation Department - National Museum of Denmark and Kirsten Trampedach, Senior Conservator at the National Museum of Denmark, for the stimulating discussions about the valuable wall painting in Nebbelunde, for joining us during on-site investigation mission and for help with the permits; Birgitte Flensburg, Vicar at Nebbelunde Church, Birthe Måhr, head of Church Council and Michael Viid Thage, Churchwarden, are acknowledged for their help in the logistics of the survey campaign.

\section{REFERENCES}

[1] K. Fukunaga, I. Hosako, Y. Kohdzuma, T. Koezuka, M.-J. Kim, T. Ikari and X. Du, "Terahertz analysis of an East Asian historical mural painting," Journal of the European Optical Society - Rapid publications, vol. 5, 2010.

[2] J. B. Jackson, M. R. Mourou and J. F. Whitaker, "Terahertz TimeDomain Reflectometry Applied to the Investigation of Hidden Mural Paintings," in Conference on Lasers and Electro-Optics, San Jose, California, 2008.

[3] K. Trampedach and M. C. Christiansen, private communication, 2013. 